University of Wollongong

Research Online

Faculty of Engineering and Information

Faculty of Engineering and Information

Sciences - Papers: Part A

Sciences

$1-1-2013$

\title{
A forward osmosis-membrane distillation hybrid process for direct sewer mining: system performance and limitations
}

Ming Xie

University of Wollongong, mx504@uowmail.edu.au

Long D. Nghiem

University of Wollongong, longn@uow.edu.au

William E. Price

University of Wollongong, wprice@uow.edu.au

Menachem Elimelech

Yale University

Follow this and additional works at: https://ro.uow.edu.au/eispapers

Part of the Engineering Commons, and the Science and Technology Studies Commons

Research Online is the open access institutional repository for the University of Wollongong. For further information contact the UOW Library: research-pubs@uow.edu.au 


\title{
A forward osmosis-membrane distillation hybrid process for direct sewer mining: system performance and limitations
}

\begin{abstract}
This study demonstrates the robustness and treatment capacity of a forward osmosis (FO)-membrane distillation (MD) hybrid system for small-scale decentralized sewer mining. A stable water flux was realized using a laboratory-scale FO-MD hybrid system operating continuously with raw sewage as the feed at water recovery up to $80 \%$. The hybrid system also showed an excellent capacity for the removal of trace organic contaminants (TrOCs), with removal rates ranging from 91 to $98 \%$. The results suggest that TrOC transport through the FO membrane is governed by "solute-membrane" interaction, whereas that through the MD membrane is strongly correlated to TrOC volatility. Concentrations of organic matter and TrOCs in the draw solution increased substantially as the water recovery increased. This accumulation of some contaminants in the draw solution is attributed to the difference in their rejection by the FO and MD systems. We demonstrate that granular activated carbon adsorption or ultraviolet oxidation could be used to prevent contaminant accumulation in the draw solution, resulting in near complete rejection (>99.5\%) of TrOCs.
\end{abstract}

\section{Keywords}

limitations, osmosis, membrane, distillation, hybrid, process, direct, sewer, mining, system, performance, forward

\section{Disciplines}

Engineering | Science and Technology Studies

\section{Publication Details}

Xie, M., Nghiem, L. D., Price, W. E. \& Elimelech, M. (2013). A forward osmosis-membrane distillation hybrid process for direct sewer mining: system performance and limitations. Environmental Science \& Technology, 47 (23), 13486-13493. 


\title{
A Forward Osmosis - Membrane Distillation Hybrid Process for Direct Sewer Mining: System Performance and Limitations
}

\author{
Ming Xie ${ }^{1}$, Long D. Nghiem ${ }^{1, *}$, William E. Price ${ }^{2}$, and Menachem Elimelech ${ }^{3}$ \\ ${ }^{1}$ Strategic Water Infrastructure Laboratory, School of Civil, Mining and Environmental \\ Engineering, University of Wollongong, Wollongong, NSW 2522, Australia \\ ${ }^{2}$ Strategic Water Infrastructure Laboratory, School of Chemistry, University of Wollongong, \\ Wollongong, NSW 2522, Australia \\ ${ }^{3}$ Department of Chemical and Environmental Engineering, Yale University, New Haven, CT \\ 06520-8286, United States
}

* Corresponding author: Long D. Nghiem, Phone: +61 24221 4590, Fax: + 6124221 3238. Email: longn@uow.edu.au 


\section{ABSTRACT}

This study demonstrates the robustness and treatment capacity of a forward osmosis (FO) membrane distillation (MD) hybrid system for small-scale decentralized sewer mining. A stable water flux was realized using a laboratory-scale FO-MD hybrid system operating continuously with raw sewage as the feed at water recovery up to $80 \%$. The hybrid system also showed an excellent capacity for the removal of trace organic contaminants (TrOCs), with removal rates ranging from 91 to $98 \%$. The results suggest that TrOC transport through the FO membrane is governed by 'solute - membrane' interaction, while that through the MD membrane is strongly correlated to TrOC volatility. Concentrations of organic matter and TrOCs in the draw solution increased substantially as the water recovery increased. This accumulation of some contaminants in the draw solution is attributed to the difference in their rejection by the FO and MD systems. We demonstrate that granular activated carbon adsorption or ultraviolet oxidation could be used to prevent contaminant accumulation in the draw solution, resulting in near complete rejection $(>99.5 \%)$ of TrOCs.

\section{TOC Art}






\section{INTRODUCTION}

In modern urban water management, sewage can be a resource for recovering clean water ${ }^{1}$, energy $^{2}$, and nutrients ${ }^{3}$. In fact, extracting clean water from sewage has been practiced in numerous centralized water reclamation plants to augment water supply and attenuate drought ${ }^{4}$. However, these centralized engineered systems can be capital and energy intensive ${ }^{5,6}$. In these systems, the collection and conveyance of wastewater to the point of treatment and the distribution of recycled water to the end users are energy intensive and result in an average emission of 0.9 kilogram of $\mathrm{CO}_{2}$ equivalent per cubic meter of reclaimed water ${ }^{7}$. Energy consumption and capital investment can be significantly higher in cities with aging distribution systems ${ }^{8}$. As a result, decentralized technologies have emerged as an attractive alternative for water recycling.

Sewer mining is a decentralized water recycling technique where wastewater is extracted from the existing sewer system, directly treated, and then recycled for on-site use, usually for non-potable purposes. Several sewer mining initiatives, mostly in Australia, have been demonstrated in recent years 9,10 . The reclaimed water from sewer mining is used for irrigating golf courses and public parks, laundry water make-up, and toilet flushing in commercial buildings.

A major technical challenge for further implementation of sewer mining is the development of a treatment process that can produce high treated water quality from raw sewage and is sufficiently simple and robust for decentralized applications. Several recent studies have suggested that forward osmosis (FO) can be an excellent platform to advance sewer mining ${ }^{11-13}$. FO has demonstrated its robustness and effectiveness for treating low quality feed water, such as digested sludge ${ }^{14,15}$, sewage ${ }^{16-18}$, and produced water from oil and gas exploration ${ }^{19}$. As a result, the use of FO followed by either reverse osmosis (RO) ${ }^{20}$ or eletrodialysis (ED) ${ }^{21}$ for sewer mining has recently been explored. These systems take advantage of the inherent lowfouling propensity of FO to provide pre-treatment for the subsequent RO or ED, which is used for draw solute and clean water recoveries. Hancock et al ${ }^{22}$ conducted pilot study and demonstrated that FO membrane fouling in a pilot-scale FO-RO hybrid system was largely reversible after 1300-hours operation. Another advantage of these hybrid systems is the double barrier against feed contaminant permeation, thereby ensuring high quality product water. 
Hancock et al. ${ }^{20}$ reported that overall rejections of 23 trace organic contaminants (TrOCs) were above $99 \%$ for a closed-loop FO-RO hybrid system. A recent study by Zhang et al. ${ }^{21}$ indicated that product water from an FO-ED hybrid system for wastewater treatment meets drinking water standards.

Membrane distillation (MD), which is a thermally driven membrane separation process, has also emerged as a potential process to be integrated with FO. In MD, the temperature of feed solution (i.e. the diluted draw solution of the FO process) is increased to induce the transport of water vapor across a hydrophobic, microporous membrane, which then condenses to the liquid form. MD offers complete rejection of non-volatile substances in feed solution ${ }^{23}$. In addition, MD efficiency is independent of feed water salinity, allowing for desalination of high salinity water with low-grade heat ${ }^{24}$.

The feasibility of a FO-MD hybrid system has been examined by concentrating solutions

containing valuable industrial chemicals or pharmaceuticals. Wang et al. ${ }^{25}$ employed a benchscale FO-MD hybrid system to treat highly viscous protein solution. In this FO-MD hybrid system, FO was employed for dewatering protein solutions while MD was used for draw solution recovery. Another bench-scale FO-MD hybrid system was used to concentrate a dye solution, where the hybrid system efficiency was maximized by a balanced water flux of the FO and MD processes $^{26}$.

Despite recent efforts to understand the FO-MD hybrid system, investigations to evaluate the system for direct sewer mining are rather scarce. In this paper, we aimed to evaluate the performance of the FO-MD hybrid system in terms of water production and TrOC rejection for direct sewer mining. Limitations of the FO-MD hybrid system were identified by examining TrOC transport behavior in FO and MD processes. Furthermore, corresponding approaches were also proposed and examined to mitigate the limitations of the FO-MD hybrid system.

\section{MATERIALS AND METHODS}

FO and MD Membranes. A flat-sheet, cellulose-based membrane from Hydration Technology Innovations (Albany, OR) was used for the FO process. The FO membrane is composed of a cellulose triacetate layer with an embedded woven support mesh ${ }^{27}$. A hydrophobic, microporous membrane from Porous Membrane Technology (Ningbo, China) was used for the MD process. The MD membrane consists of a thin polytetrafluoroethylene (PTFE) 
active layer on top of a polypropylene (PP) support layer. Key properties of the FO and MD membranes are summarized in Table S1 of the Supporting Information.

Representative Wastewater Feed and Trace Organic Contaminants. Raw sewage was collected from a sewage treatment plant (Wollongong, New South Wales, Australia) after mechanical screening and was used without further processing in our lab-scale experiments. The raw sewage had a $\mathrm{pH}$ value of 7.1 , conductivity of $1075 \mu \mathrm{S} \mathrm{cm}^{-1}$, and total organic carbon of $72 \mathrm{mg} \mathrm{L}{ }^{-1}$. The raw sewage sample was kept at $4{ }^{\circ} \mathrm{C}$ and used within one week. Key water quality parameters were monitored before each experiment, and their variations were less than $5 \%$.

A stock solution containing $1 \mathrm{~g} \mathrm{~L}^{-1}$ of each of 12 representative TrOCs (Table S2 of the Supporting Information) was prepared in pure methanol. The stock solution was kept at $-18{ }^{\circ} \mathrm{C}$ in the dark and used within one month. The TrOCs were selected to cover a diverse range of properties, including charge, volatility, hydrophobicity, and molecular weight (Table S2, Supporting Information). They are frequently detected in raw sewage in the range from hundreds of nanograms per liter $\left(n g \mathrm{~L}^{-1}\right)$ to several micrograms per liter $\left(\mu \mathrm{g} \mathrm{L}^{-1}\right)$.

Forward Osmosis - Membrane Distillation (FO-MD) System. The FO-MD hybrid system used in this study consisted of an FO membrane cell, a direct contact MD membrane cell, circulation pumps, and temperature control equipment (Figure 1). The FO and MD membrane cells were practically identical. They were made of acrylic plastic to minimize heat loss to the surroundings and designed to hold a flat-sheet membrane under moderate pressure differential without any physical support. The flow channels were engraved in the acrylic blocks that make up the feed and permeate semi-cells. Each channel is $3 \mathrm{~mm}$ deep, $95 \mathrm{~mm}$ wide, and $145 \mathrm{~mm}$ long.

\section{FIGURE 1}

In the FO-MD hybrid system, the draw solution reservoir of the FO process was also the feed reservoir for the MD process. Variable speed gear pumps (Micropump, Vancouver, WA) were used to circulate the feed, draw, and distillate solutions at a cross-flow velocity of $9 \mathrm{~cm} / \mathrm{s}$. The feed solution temperature was maintained at $20{ }^{\circ} \mathrm{C}$ using a water bath (Neslab RTE 7 , Thermo Scientific, Waltham, MA). A temperature sensor was inserted before the inlet of the feed solution to the direct contact MD membrane cell. The temperature sensor and a heating element were connected to a temperature control unit that maintained the draw solution temperature at 
$40{ }^{\circ} \mathrm{C}$. The MD distillate temperature was maintained at $20{ }^{\circ} \mathrm{C}$ using another water bath (Neslab RTE 7, Thermo Scientific, Waltham, MA) and was monitored continuously using a digital thermometer. Weight changes of the draw and distillate reservoirs were recorded by digital balances (Mettler Toledo, Hightstown, NJ) connected to a computer.

The FO-MD hybrid system could be integrated with either granular activated carbon (GAC) or ultraviolet (UV) treatment (Figure S1, Supporting Information) to mitigate the accumulation organic contaminants in the draw solution (Section 3.4). In each experiment, 0.25 g of GAC (GAC-1200, Activated Carbon Technologies, Victoria, Australia) was packed in a small tube connected to the outlet flow from the draw solution to the MD membrane cell. In this configuration, the draw solution was continuously circulated through the GAC column, and no breakthrough of TrOCs was observed for the entire duration of the experiment. A UV oxidation reactor (Ace Glass, Vineland, NJ) consisting of a reactor and a low-pressure mercury lamp was used. The reactor had an effective volume of $0.4 \mathrm{~L}$ and a cooling water jacket. The low-pressure mercury lamp had a length, total UV energy output, and UV intensity of $27 \mathrm{~cm}, 83 \mathrm{~W}$, and 1.04 $\mathrm{W} \mathrm{cm}{ }^{-2}$, respectively. The UV oxidation reactor was operated intermittently for $25 \mathrm{~min}$ at a flowrate of $80 \mathrm{~mL} \mathrm{~min}^{-1}$ to treat draw solution after every $2 \mathrm{~L}$ of permeate had been produced from the FO-MD hybrid system.

Experimental Protocol for FO-MD System Operation. Three bench-scale experiments were performed using the FO-MD hybrid system and MD system alone. Two types of feed solutions were prepared by adding the TrOC stock solution into either a background electrolyte solution containing $1 \mathrm{mM} \mathrm{NaHCO}$ and $20 \mathrm{mM} \mathrm{NaCl}$ in Milli-Q water (denoted as "clean feed") or raw sewage (denoted as "sewage feed") to obtain an initial concentration of $5 \mu \mathrm{g}$ $\mathrm{L}^{-1}$ for each TrOC.

Both clean and sewage feeds were processed continuously by the FO-MD hybrid system to achieve $80 \%$ water recovery. Initial volumes for feed, draw, and distillate solutions were 10, 2 , and $1 \mathrm{~L}$, respectively. For the $\mathrm{FO}$ process, $1.5 \mathrm{M} \mathrm{NaCl}$ draw solution at $40{ }^{\circ} \mathrm{C}$ generated a water flux of $8 \mathrm{Lm}^{-2} \mathrm{~h}^{-1}$. In the MD process, the same water flux was obtained at draw and distillate temperatures of 40 and $20{ }^{\circ} \mathrm{C}$, respectively. Water flux of the FO-MD hybrid system was recorded continuously, while that of the FO process was recorded intermittently when the FO process was disconnected from the MD process to facilitate draw solution sampling. Feed, draw, 
and distillate tanks were sealed by a laboratory-grade paraffin film (Novix-II, Iwaki Glass, Japan) to prevent evaporation loss during the experiment. The tank volumes at the conclusion of each experiment varied by less than $7 \%$. Feed, draw, and distillate samples were taken at various water recoveries, and their sample volumes were $0.25,0.5$ and $1 \mathrm{~L}$, respectively, depending on TrOC concentration in each sample.

Sewage feed was also treated by the MD system alone, reaching $80 \%$ water recovery. Initial volumes for the feed and distillate were 5 and $1 \mathrm{~L}$, respectively. The MD system alone was operated at the same water flux as the FO-MD hybrid system, where feed and distillate temperatures were 40 and $20{ }^{\circ} \mathrm{C}$, respectively. Feed and distillate samples were taken at various water recoveries, and their sample volumes were 0.25 and $1 \mathrm{~L}$, respectively.

Analytical Methods. TrOC concentrations in the feed, draw, and distillate solution samples were determined using an analytical method described elsewhere ${ }^{28}$. This method involved solid phase extraction followed by liquid chromatography - mass spectrometry (LCMS) analysis using a Shimadzu LC/MS system (LCMS 2020, Shimadzu, Kyoto, Japan) with an electrospray ionization interface.

Total organic carbon (TOC) and total nitrogen (TN) of the feed, draw, and distillate samples were determined using a TOC/TN analyser (TOC-V $\mathrm{V}_{\mathrm{CSH}}$, Shimadzu, Kyoto, Japan). $\mathrm{UV}_{254}$ absorbance was measured using a UV-Vis spectrophotometer (UV-1700, Shimadzu, Kyoto, Japan) at a wavelength of $254 \mathrm{~nm}$. Solution $\mathrm{pH}$ and electric conductivity were measured using an Orion 4-Star Plus pH/conductivity meter (Thermo Scientific, Waltham, MA).

Contact angle measurements of the virgin and fouled MD membranes were conducted using a Rame-Hart Goniometer (Model 250, Rame-Hart, Netcong, NJ) employing the standard sessile drop method. Prior to measurement, the virgin and fouled membrane samples were dried for over 24 hours in a desiccator. The contact angle of each membrane was determined from an average of ten water droplets (Milli-Q water).

\section{RESULTS AND DISCUSSION}

Water Production by the FO - MD System. Results from this study show that FO is an effective pre-treatment barrier for the subsequent MD process. The FO pre-treatment step 
ensured a stable water flux by the MD process in the FO-MD hybrid system when raw sewage was directly used as the feed (Figure 2A). By contrast, when raw sewage was fed directly to the MD process without the FO pre-treatment step, significant water flux decline was observed. This decrease in the MD water flux is attributed to membrane fouling caused by the deposition of organic and particulate matter on the membrane surface (Figure S2, Supporting Information). Membrane fouling not only restricted the active surface area available for the transport of water vapour in the MD process, but also significantly reduced the membrane surface hydrophobicity as indicated by the decrease of the contact angle from $135 \pm 15^{\circ}$ for the virgin membrane to $58 \pm$ $11^{\circ}$ for the fouled membrane. Maintaining the hydrophobicity of the MD membrane to prevent pore wetting and water entrance into the pore is critical for effective separation by the MD process ${ }^{29}$.

\section{FIGURE 2}

FO is very resistant to membrane fouling, particularly at a low water flux ${ }^{28,30}$. In fact, identical water fluxes were obtained with both raw sewage and a clean feed solution with a similar electrical conductivity (Figure 2B). It is noteworthy that there is a small water flux decline in both cases. However, this decrease was caused by salinity build-up in the feed due to reverse draw solution permeation rather than membrane fouling. The build-up in salinity led to an increase in the feed osmotic pressure and hence a decrease in the overall driving force in the FO process. Similar observations have been reported by Hancock et al. ${ }^{20}$ who examined the water flux using wastewater effluent as feed in a pilot-scale FO process.

\section{Removal of Salt, Organic Matter, and Trace Organic Contaminants by the} FO - MD System. Both the FO-MD hybrid system and the MD system alone effectively rejected inorganic salts (indicated by electrical conductivity measurement) and organic matter (indicated by TOC, TN, and $\mathrm{UV}_{254}$ measurement) (Figure 3). The observed overall high rejection can be largely attributed to the MD process where only water vapor is transported through the membrane pores ${ }^{31}$.

\section{FIGURE 3}

TrOC rejection in the MD process was strongly correlated with compound volatility (Figure 4A). Specifically, non-volatile TrOCs with Henry's law constants $\left(p \mathrm{~K}_{\mathrm{H}}\right)$ above 8 could be completely rejected. However, semi-volatile TrOCs with $p \mathrm{~K}_{\mathrm{H}}$ values less than 7 (i.e., 
pentachlorophenol, triclosan, linuron, and atrazine) exhibited varying rejection rates, ranging from 70 to less than $90 \%$. This strong correlation of compound rejection with volatility is a direct consequence that vapor pressure difference is the driving force for mass transfer in MD.

\section{FIGURE 4}

TrOC rejection was significantly affected by "solute - membrane" interaction in FO (Figure $4 \mathrm{~B})^{20,32}$. At the experimental $\mathrm{pH}$ value of 7.1, the FO membrane is negatively charged (Table S1, Supporting Information) and electrostatic interaction is an important rejection mechanism of charged solutes ${ }^{33,34}$. More importantly, these charged TrOC solutes are hydrated, which significantly increases their apparent molecular sizes ${ }^{35}$. Thus, both electrostatic interaction and size exclusion resulted in more than $90 \%$ rejection of charged TrOCs. Size exclusion also governs the rejection of neutral TrOCs, which led to lower rejection of TrOCs with low molecular weights (i.e., caffeine and primidone). In addition, low rejections of two hydrophobic TrOCs, linuron and pentachlorophenol, were due to an adsorption - diffusion mechanism, where the adsorption of hydrophobic TrOC solutes to the membrane subsequently facilitates their diffusion through the membrane polymeric matrix ${ }^{36,37}$.

Although TrOC rejection varied in the FO process, the synergetic effect of the FO-MD hybrid system substantially enhanced the overall TrOC rejection (Figure 4B). The MD process complemented well the FO process, particularly for the removal of hydrophobic or semi-volatile TrOCs (i.e. pentachlorophenol, triclosan, linuron, and atrazine) that were only moderately removed by either process individually. As a result, TrOC concentrations in the product water of the FO-MD hybrid system were much lower than those for the MD system alone (Figure 5). In particular, concentrations of pentachlorophenol and atrazine were one order of magnitude lower than their concentration limits in drinking water regulations ${ }^{38}$.

\section{FIGURE 5}

Contaminant Accumulation in the FO - MD System. Despite the high performance and potential promise of the FO-MD hybrid system, this closed-loop system is not without its limitations. Contaminants that permeate through the FO but not the MD process can accumulate in the draw solution. We have observed a notable build-up of organic matter in the draw solution, which increased as the cumulative permeate volume increased (Figure 6A). In 
addition, concentrations of five TrOCs in the draw solution, with less than $90 \%$ rejection by the FO process (Figure 4B), also increased substantially as water recovery increased (Figure 6B).

\section{FIGURE 6}

This detrimental accumulation phenomenon was mainly driven by the near complete rejection of non-volatile solutes by the MD membrane in the FO-MD hybrid system. TrOC rejection by the MD membrane was significantly higher than that for the FO membrane, thereby leading to an undesirable TrOC accumulation in the draw solution. We note that similar contaminant accumulation could happen in an FO-RO hybrid system, where the RO membrane has higher rejection than the FO membrane ${ }^{39}$. D'Haese et al. ${ }^{40}$ modelled the TrOC accumulation in an FO-RO hybrid system and predicted that an elevated TrOC concentration in the draw solution deteriorated the product water quality. As a result, mitigation strategies should be implemented to minimize TrOC accumulation, thereby enhancing system sustainability and securing product water quality in the FO-MD hybrid system.

Mitigating Contaminant Accumulation in the FO - MD System. Either GAC adsorption or UV oxidation effectively mitigated the accumulation of organic matter and TrOCs in the FO-MD hybrid system (Figures 7 and 8). Both approaches reduced the concentrations of organic matter by one order of magnitude and suppressed their accumulation in the draw solution (Figure 7). Notably, either approach reduced TrOC concentrations by two orders of magnitude (Figure 8).

\section{FIGURE 7}

\section{FIGURE 8}

GAC adsorption was favoured by the high ionic strength of the draw solution (i.e., $1.5 \mathrm{M}$ $\mathrm{NaCl}$ ), thereby inducing a "salting-out" effect ${ }^{41}$ and reducing TrOC solubility in the aqueous phase. On the other hand, UV oxidation was correlated to the molecular structure of the contaminants. TrOCs possessing halogenated functional groups (atrazine, pentachlorophenol, and linuron) or aromatic benzene ring (primidone) are amenable to UV photodegradation by

substitution of halogens and subsequent dealkylation ${ }^{42}$. As a result, the FO-MD hybrid system coupled to either GAC adsorption or UV oxidation achieved near complete TrOC rejection 
$(>99.5 \%)$ with negligible TrOC concentrations in the product water (Figure S3, Supporting Information).

Despite the effectiveness of GAC adsorption and UV oxidation in mitigating accumulation of solutes in the draw solution, long-term operation concerns should be considered. Periodic replacement or regeneration of GAC should be conducted before TrOC breakthrough occurs as a result of reaching maximum GAC adsorption ${ }^{43}$. For the UV oxidation, there remain uncertainties regarding the impact of oxidation by-products or oxidation residuals on the membrane polymer and product water quality.

Implications for Sewer Mining. Stable water production and high product water quality imply robust capacity of the FO-MD hybrid system in sewer mining. These results highlight the benefits of the FO-MD hybrid system. Low operating hydraulic pressure of the FOMD hybrid system substantially lowers the technical barrier for small-scale implementation, thereby favoring decentralized sewer mining. In addition, the energy consumption of the FO-MD hybrid system could be further compensated by utilizing industrial waste heat and natural solar or geothermal energies. Thus, the FO-MD hybrid system becomes attractive in arid areas where solar energy and other forms of low-grade heat are abundant and readily available.

\section{AUTHOR INFORMATION}

\section{Corresponding author}

* Phone: +61 24221 4590. Fax: + 6124221 3238. Email: longn@uow.edu.au

\section{Notes}

The authors declare no competing financial interest.

\section{ACKNOWLEDGMENTS}

The authors would like to thank Hydration Technology Innovations and Porous Membrane Technology for providing membrane samples. University of Wollongong is acknowledged for 
the provision of a doctoral scholarship to M.X.. Financial support from Australia - China Science and Research Funding: Group Mission (ACSRF06443) is also acknowledged.

\section{ASSOCIATED CONTENTS}

\section{Supporting Information}

Details on key properties of FO and MD membranes (Table S1), physicochemical properties of representative trace organic contaminants (Table S2), panoramic view of the FO-MD hybrid system with mitigation loop (Figure S1), MD membrane autopsy at the conclusion of the experiment (Figure S2), and comparison of TrOC concentrations in feed, draw, and distillate solutions for: FO-MD, FO-MD-GAC adsorption, and FO-MD-UV oxidation (Figure S3). This information is available free of charge via the Internet at http://pubs.acs.org/.

\section{References}

1. Elimelech, M.; Phillip, W. A., The Future of Seawater Desalination: Energy, Technology, and the Environment. Science 2011, 333, 712-717.

2. Logan, B. E.; Elimelech, M., Membrane-based processes for sustainable power generation using water. Nature 2012, 488, 313-319.

3. Grant, S. B.; Saphores, J.-D.; Feldman, D. L.; Hamilton, A. J.; Fletcher, T. D.; Cook, P. L. M.; Stewardson, M.; Sanders, B. F.; Levin, L. A.; Ambrose, R. F.; Deletic, A.; Brown, R.; Jiang, S. C.; Rosso, D.; Cooper, W. J.; Marusic, I., Taking the "Waste" Out of "Wastewater" for Human Water Security and Ecosystem Sustainability. Science 2012, 337, 681-686.

4. Shannon, M. A.; Bohn, P. W.; Elimelech, M.; Georgiadis, J. G.; Marinas, B. J.; Mayes, A. M., Science and technology for water purification in the coming decades. Nature 2008, 452, 301310 .

5. Gleick, P. H., Global Freshwater Resources: Soft-Path Solutions for the $21^{\text {st }}$ Century. Science 2003, 302, 1524-1528.

6. Vorosmarty, C. J.; McIntyre, P. B.; Gessner, M. O.; Dudgeon, D.; Prusevich, A.; Green, P.; Glidden, S.; Bunn, S. E.; Sullivan, C. A.; Liermann, C. R.; Davies, P. M., Global threats to human water security and river biodiversity. Nature 2010, 467, 555-561.

7. Hall, M. R.; West, J.; Sherman, B.; Lane, J.; de Haas, D., Long-Term Trends and Opportunities for Managing Regional Water Supply and Wastewater Greenhouse Gas Emissions. Environ. Sci. Technol. 2011, 45, 5434-5440. 
8. Vince, F.; Aoustin, E.; Bréant, P.; Marechal, F., LCA tool for the environmental evaluation of potable water production. Desalination 2008, 220, (1-3), 37-56.

9. Butler, R.; MacCormick, T., Opportunities for decentralized treatment, sewer mining and effluent re-use. Desalination 1996, 106, 273-283.

10. Chanan, A.; Woods, P., Introducing total water cycle management in Sydney: a Kogarah Council initiative. Desalination 2006, 187, 11-16.

11. Cath, T. Y.; Childress, A. E.; Elimelech, M., Forward osmosis: Principles, applications, and recent developments. J. Mem. Sci. 2006, 281, 70-87.

12. Zhao, S.; Zou, L.; Tang, C. Y.; Mulcahy, D., Recent developments in forward osmosis: Opportunities and challenges. J. Mem. Sci. 2012, 396, 1-21.

13. Hoover, L. A.; Phillip, W. A.; Tiraferri, A.; Yip, N. Y.; Elimelech, M., Forward with Osmosis: Emerging Applications for Greater Sustainability. Environ. Sci. Technol. 2011, 45, 9824-9830.

14. Holloway, R. W.; Childress, A. E.; Dennett, K. E.; Cath, T. Y., Forward osmosis for concentration of anaerobic digester centrate. Water Res. 2007, 41, 4005-4014.

15. Nguyen, N. C.; Chen, S.-S.; Yang, H.-Y.; Hau, N. T., Application of forward osmosis on dewatering of high nutrient sludge. Bioresource Technol. 2013, 132, 224-229.

16. Cornelissen, E. R.; Harmsen, D.; de Korte, K. F.; Ruiken, C. J.; Qin, J.-J.; Oo, H.; Wessels, L. P., Membrane fouling and process performance of forward osmosis membranes on activated sludge. J. Mem. Sci. 2008, 319, 158-168.

17. Cath, T. Y.; Gormly, S.; Beaudry, E. G.; Flynn, M. T.; Adams, V. D.; Childress, A. E., Membrane contactor processes for wastewater reclamation in space: Part I. Direct osmotic concentration as pretreatment for reverse osmosis. J. Mem. Sci. 2005, 257, 85-98.

18. Lutchmiah, K.; Cornelissen, E. R.; Harmsen, D. J. H.; Post, J. W.; Lampi, K.; Ramaekers, H.; Rietveld, L. C.; Roest, K., Water recovery from sewage using forward osmosis. Water Sci. Technol. 2011, 64, 1443-1449.

19. McGinnis, R. L.; Hancock, N. T.; Nowosielski-Slepowron, M. S.; McGurgan, G. D., Pilot demonstration of the $\mathrm{NH}_{3} / \mathrm{CO}_{2}$ forward osmosis desalination process on high salinity brines. Desalination 2013, 312, 67-74.

20. Hancock, N. T.; Xu, P.; Heil, D. M.; Bellona, C.; Cath, T. Y., Comprehensive Bench- and Pilot-Scale Investigation of Trace Organic Compounds Rejection by Forward Osmosis. Environ. Sci. Technol. 2011, 45, 8483-8490.

21. Zhang, Y.; Pinoy, L.; Meesschaert, B.; Van der Bruggen, B., A Natural Driven Membrane Process for Brackish and Wastewater Treatment: Photovoltaic Powered ED and FO Hybrid System. Environ. Sci. Technol. 2013, 47, 10548-10555.

22. Hancock, N. T.; Xu, P.; Roby, M. J.; Gomez, J. D.; Cath, T. Y., Towards direct potable reuse with forward osmosis: Technical assessment of long-term process performance at the pilot scale. J. Mem. Sci. 2013, 445, 34-46.

23. Nghiem, L. D.; Cath, T., A scaling mitigation approach during direct contact membrane distillation. Sep. Purif. Technol. 2011, 80, 315-322. 
24. Shaffer, D. L.; Arias Chavez, L. H.; Ben-Sasson, M.; Romero-Vargas Castrillón, S.; Yip, N. Y.; Elimelech, M., Desalination and Reuse of High-Salinity Shale Gas Produced Water: Drivers, Technologies, and Future Directions. Environ. Sci. Technol. 2013, 47, 9569-9583.

25. Wang, K. Y.; Teoh, M. M.; Nugroho, A.; Chung, T.-S., Integrated forward osmosismembrane distillation (FO-MD) hybrid system for the concentration of protein solutions. Chem. Eng. Sci. 2011, 66, 2421-2430.

26. Ge, Q.; Wang, P.; Wan, C.; Chung, T.-S., Polyelectrolyte-Promoted Forward OsmosisMembrane Distillation (FO-MD) Hybrid Process for Dye Wastewater Treatment. Environ. Sci. Technol. 2012, 46, 6236-6243.

27. McCutcheon, J. R.; Elimelech, M., Influence of membrane support layer hydrophobicity on water flux in osmotically driven membrane processes. J. Mem. Sci. 2008, 318, 458-466.

28. Xie, M.; Nghiem, L. D.; Price, W. E.; Elimelech, M., Impact of humic acid fouling on membrane performance and transport of pharmaceutically active compounds in forward osmosis. Water Res. 2013, 47, 4567-4575.

29. Alkhudhiri, A.; Darwish, N.; Hilal, N., Membrane distillation: A comprehensive review. Desalination 2012, 287, 2-18.

30. Mi, B.; Elimelech, M., Chemical and physical aspects of organic fouling of forward osmosis membranes. J. Mem. Sci. 2008, 320, 292-302.

31. Cath, T. Y.; Adams, V. D.; Childress, A. E., Experimental study of desalination using direct contact membrane distillation: a new approach to flux enhancement. J. Mem. Sci. 2004, 228, 5-16.

32. Valladares Linares, R.; Yangali-Quintanilla, V.; Li, Z.; Amy, G., Rejection of micropollutants by clean and fouled forward osmosis membrane. Water Res. 2011, 45, 67376744.

33. Xie, M.; Price, W. E.; Nghiem, L. D., Rejection of pharmaceutically active compounds by forward osmosis: Role of solution $\mathrm{pH}$ and membrane orientation. Sep. Purif. Technol. 2012, 93, 107-114.

34. Alturki, A. A.; McDonald, J. A.; Khan, S. J.; Price, W. E.; Nghiem, L. D.; Elimelech, M., Removal of trace organic contaminants by the forward osmosis process. Sep. Purif. Technol. 2013, 103, 258-266.

35. Nghiem, L. D.; Schafer, A. I.; Elimelech, M., Role of electrostatic interactions in the retention of pharmaceutically active contaminants by a loose nanofiltration membrane. J. Mem. Sci. 2006, 286, 52-59.

36. Xie, M.; Nghiem, L. D.; Price, W. E.; Elimelech, M., Comparison of the removal of hydrophobic trace organic contaminants by forward osmosis and reverse osmosis. Water Res. 2012, 46, 2683-2692.

37. Nghiem, L. D.; Schäfer, A. I.; Elimelech, M., Removal of Natural Hormones by Nanofiltration Membranes: Measurement, Modeling, and Mechanisms. Environ. Sci. Technol. 2004, 38, 1888-1896. 
38. USEPA, National Primary Drinking Water Regulations (EPA 816-F-09-004); 2009; Available from: http://www.epa.gov/safewater/consumer/pdf/mcl.pdf.

39. Shaffer, D. L.; Yip, N. Y.; Gilron, J.; Elimelech, M., Seawater desalination for agriculture by integrated forward and reverse osmosis: Improved product water quality for potentially less energy. J. Mem. Sci. 2012, 415-416, 1-8.

40. D'Haese, A.; Le-Clech, P.; Van Nevel, S.; Verbeken, K.; Cornelissen, E. R.; Khan, S. J.; Verliefde, A. R. D., Trace organic solutes in closed-loop forward osmosis applications: Influence of membrane fouling and modeling of solute build-up. Water Res. 2013, 47, 5232-5244.

41. Delgado, L. F.; Charles, P.; Glucina, K.; Morlay, C., The removal of endocrine disrupting compounds, pharmaceutically activated compounds and cyanobacterial toxins during drinking water preparation using activated carbon-A review. Sci. Total Environ. 2012, 435-436, 509525 .

42. Lekkerkerker-Teunissen, K.; Benotti, M. J.; Snyder, S. A.; van Dijk, H. C., Transformation of atrazine, carbamazepine, diclofenac and sulfamethoxazole by low and medium pressure UV and $\mathrm{UV} / \mathrm{H}_{2} \mathrm{O}_{2}$ treatment. Sep. Purif. Technol. 2012, 96, 33-43.

43. Nguyen, L. N.; Hai, F. I.; Kang, J.; Price, W. E.; Nghiem, L. D., Coupling granular activated carbon adsorption with membrane bioreactor treatment for trace organic contaminant removal: Breakthrough behaviour of persistent and hydrophilic compounds. J. Environ. Manage. 2013, 119, 173-181. 


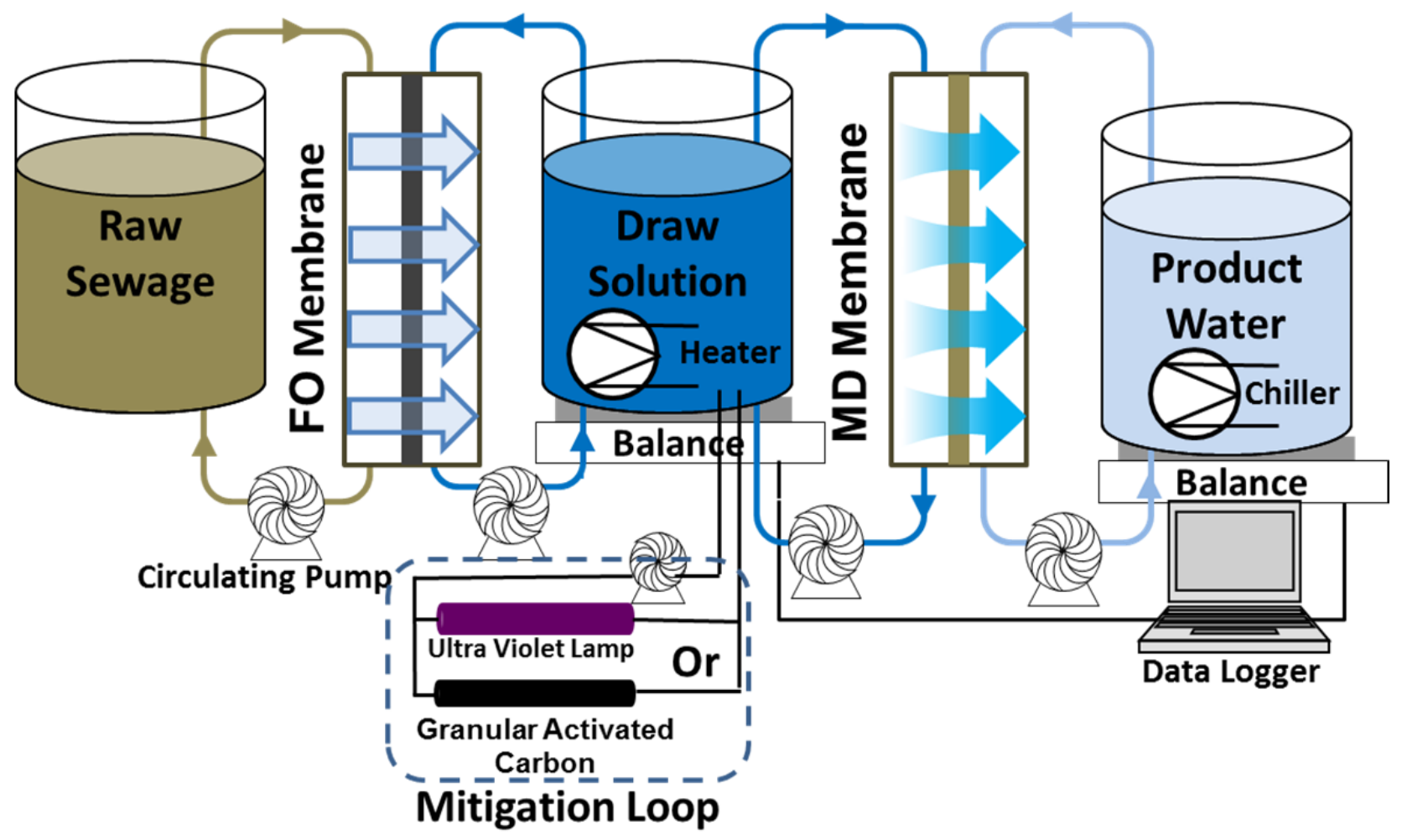

Figure 1: Schematic diagram of the forward osmosis (FO) - membrane distillation (MD) hybrid system with the mitigation loop for the reduction of the concentration of feed contaminants in the draw solution. 

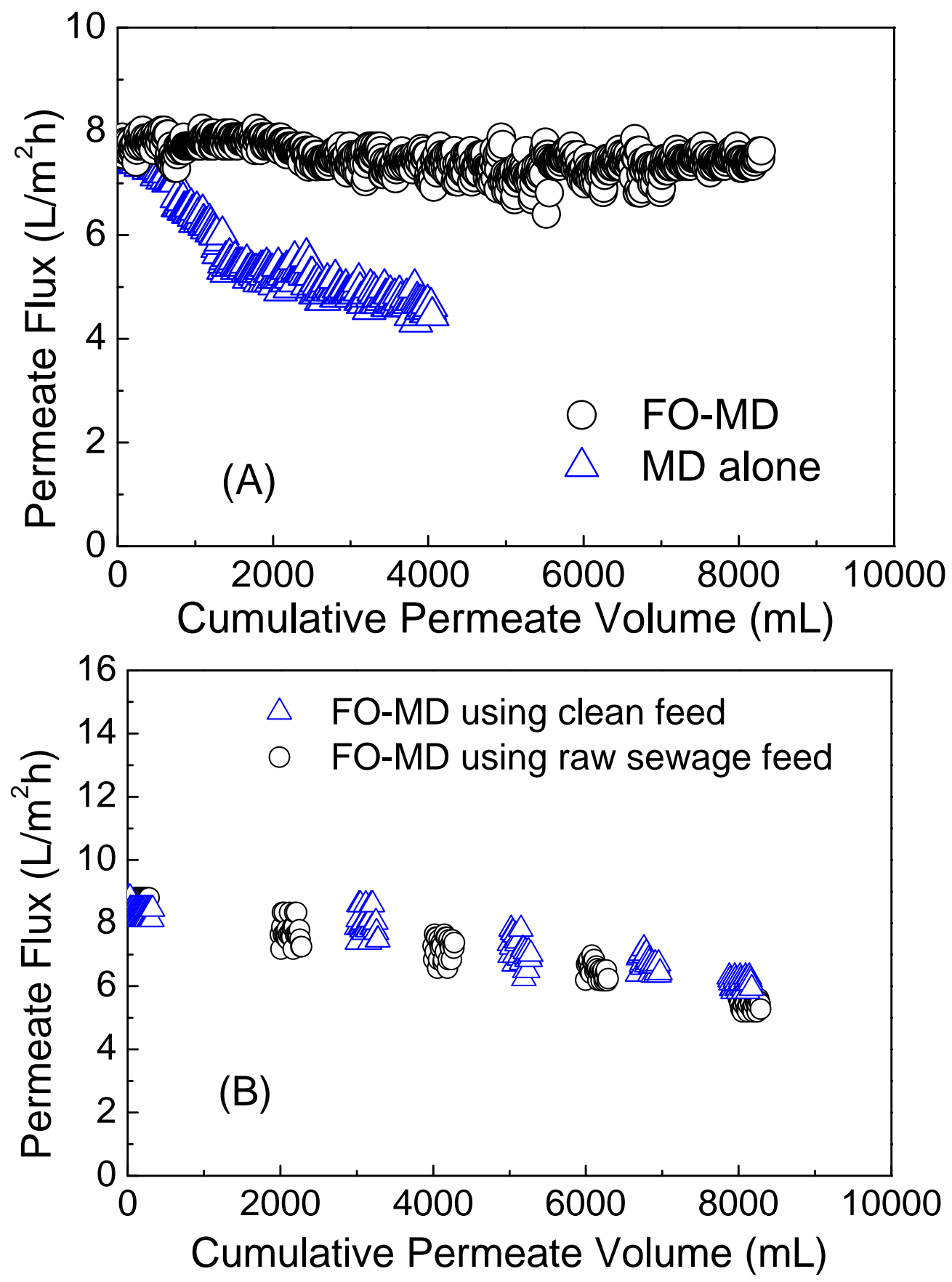

Figure 2: Water production by the FO-MD hybrid system: (A) comparison of water flux of MD alone and FO-MD hybrid systems when directly treating raw sewage, and (B) FO water flux in the FO-MD hybrid system using clean or sewage feed. For the MD alone system, initial TrOC concentrations in sewage feed were $5 \mu \mathrm{g} / \mathrm{L}$; temperatures of feed and distillate were 20 and $40{ }^{\circ} \mathrm{C}$, respectively; and cross-flow rates were $1 \mathrm{~L} / \mathrm{min}$ (corresponding to cross-flow velocity of 9 $\mathrm{cm} / \mathrm{s}$ ) for both feed and distillate. For the FO-MD hybrid system, initial TrOC concentrations in background electrolyte $\left(1 \mathrm{mM} \mathrm{NaHCO}_{3}\right.$ and $\left.10 \mathrm{mM} \mathrm{NaCl}\right)$ or sewage feed were $5 \mu \mathrm{g} / \mathrm{L}$; draw 
solution was $1.5 \mathrm{M} \mathrm{NaCl}$; temperatures of feed, draw, and distillate were 20,40 , and $20^{\circ} \mathrm{C}$, respectively; and cross-flow rates were $1 \mathrm{~L} / \mathrm{min}$ (corresponding to cross-flow velocity of $9 \mathrm{~cm} / \mathrm{s}$ ) for the feed, draw, and distillate. For the FO-MD system, a cumulative permeate volume of 8,250 $\mathrm{mL}$ was attained after about 78 hours. 

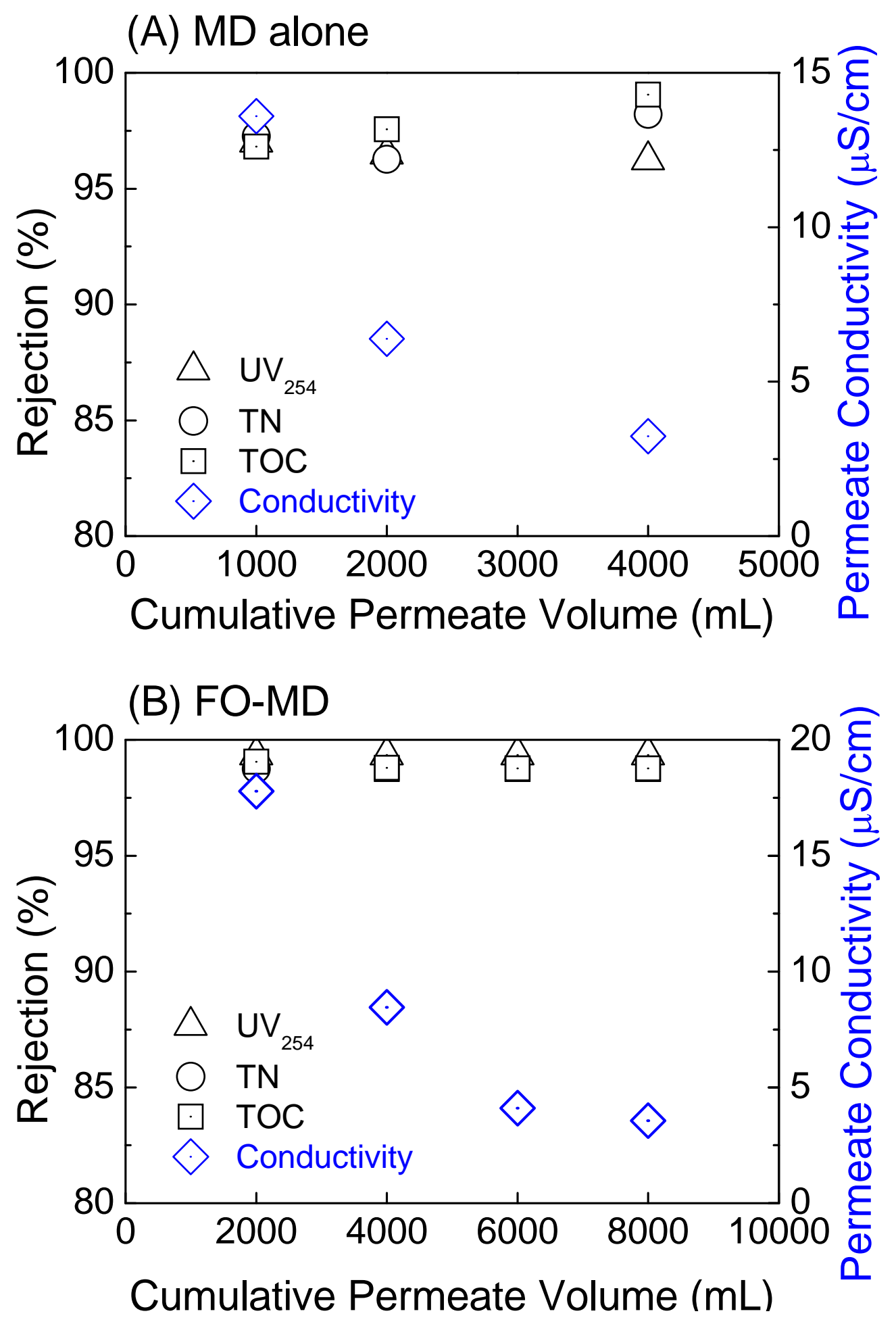

Figure 3: Rejection of total organic carbon (TOC), total nitrogen (TN), and $\mathrm{UV}_{254}$ absorbance (left axes), and conductivity of permeate or product water (right axes) for (A) MD alone system and (B) FO-MD system as a function of cumulative permeate volume. Experimental conditions are described in Figure 1. 



Figure 4: Rejection of trace organic contaminants by (A) MD alone system and (B) FO-MD system where white and grey bars represent TrOC rejection by $\mathrm{FO}$ and MD, respectively. Experimental conditions are given in Figure 1. Also shown (open circles) are the values of the Henry's law constants (presented as $\mathrm{p} K_{\mathrm{H}}=-\log K_{\mathrm{H}}$ on the right axis) for the various TrOCs. Error bars represent standard deviation from duplicate measurements. Symbols of + , -, and $n$ 
denote negatively charged, positively charged, and neutral trace organic contaminants, respectively. 


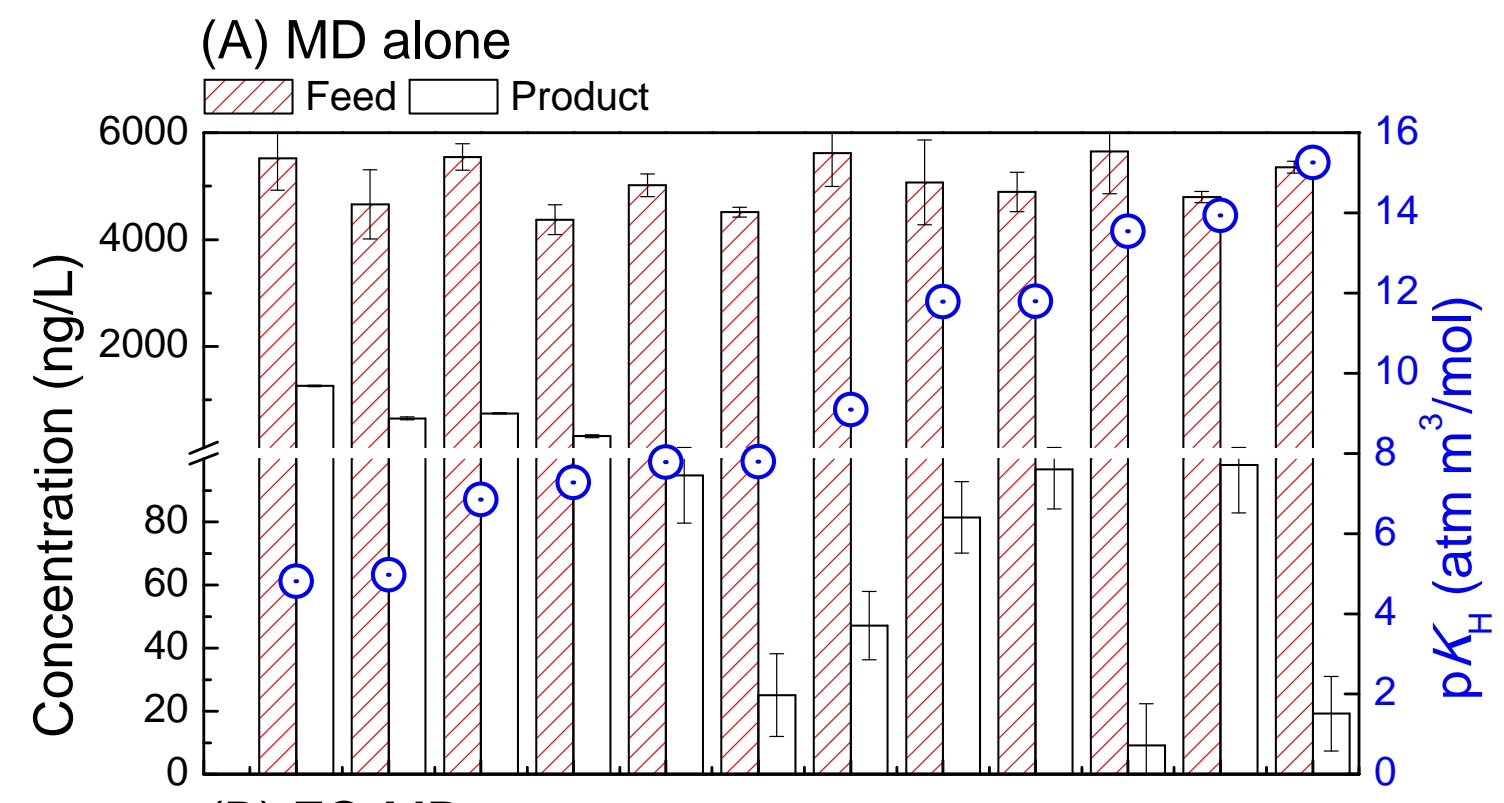

(B) FO-MD

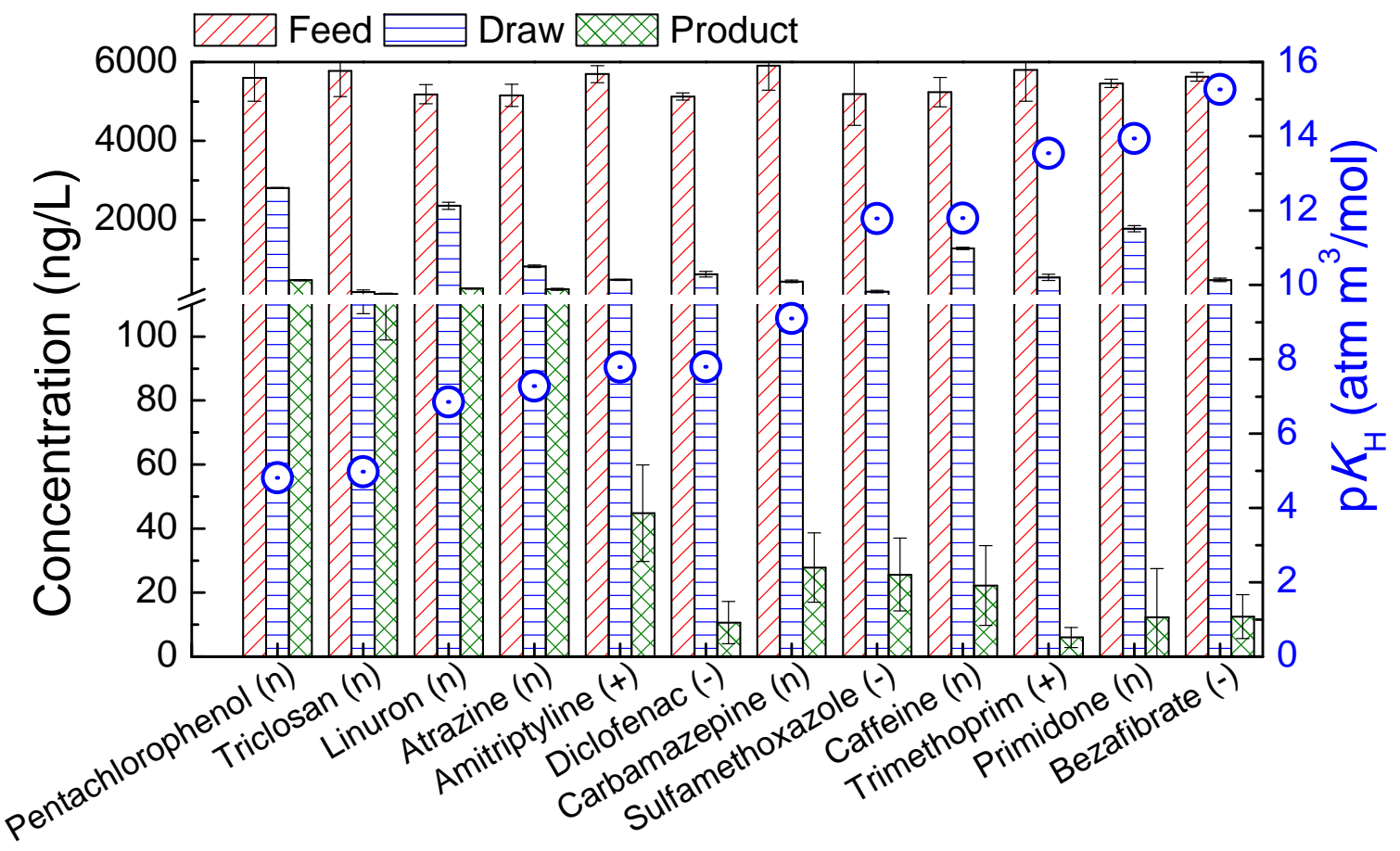

Figure 5: Concentrations of trace organic contaminants in (A) feed and product water of the MD alone system and (B) feed, draw, and product water of the FO-MD system. Experimental conditions are detailed in Figure 1. Also shown (open circles) are the values of the Henry's law constants (presented as $\mathrm{p} K_{\mathrm{H}}=-\log K_{\mathrm{H}}$ on the right axis) for the various TrOCs. Error bars represent the standard deviation from duplicate measurements. Symbols of,+- , and $n$ denote negatively charged, positively charged, and neutral trace organic contaminants, respectively. 

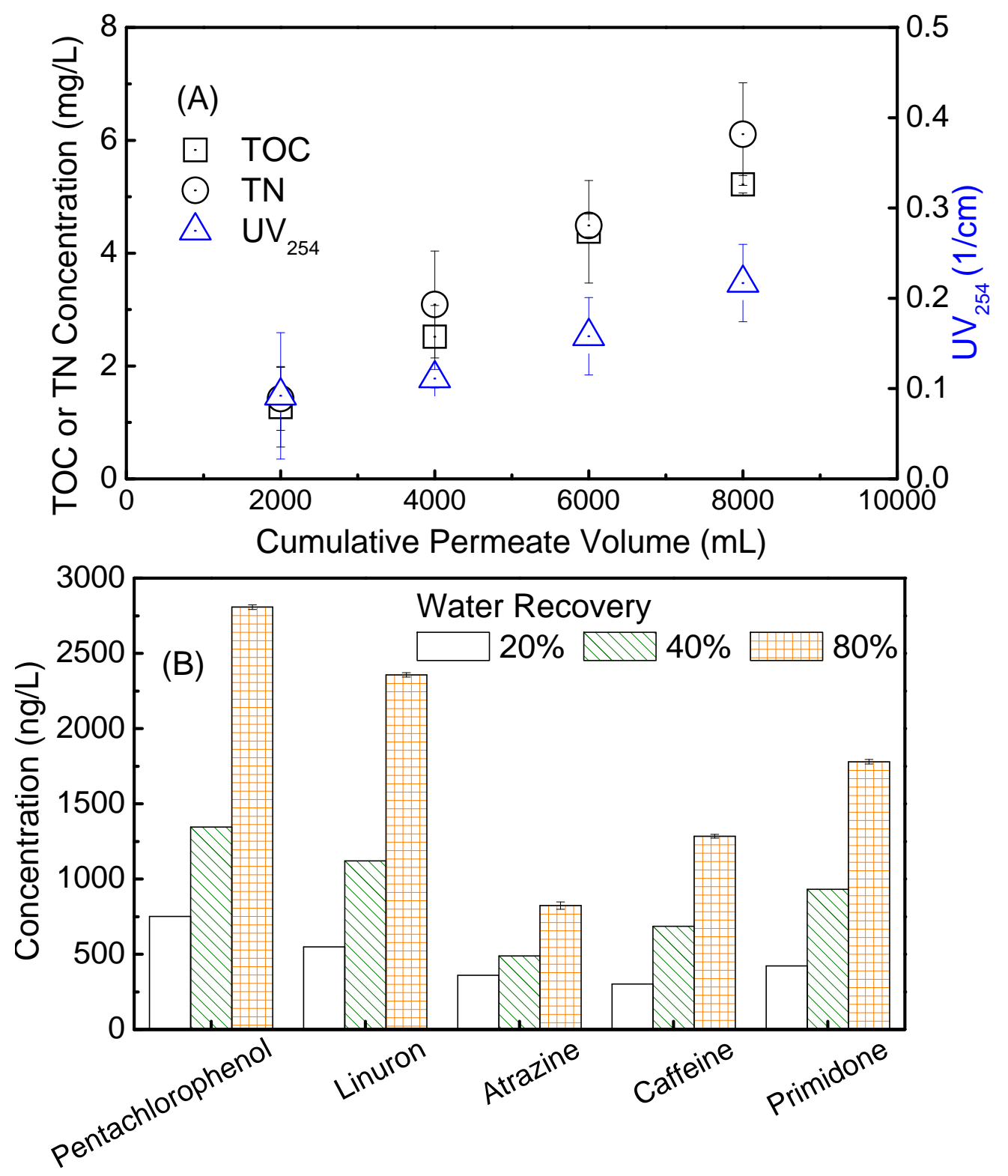

Figure 6: Accumulation of contaminants in the draw solution of the hybrid FO-MD system: (A) total organic carbon (TOC), total nitrogen (TN), and $\mathrm{UV}_{254}$ absorbance as a function of cumulative permeate volume, and (B) trace organic contaminants (with less than $90 \%$ rejection by the FO unit (Figure 3)) in the draw solution at different water recoveries. Experimental conditions are given in Figure 1. Error bars represent standard deviation from duplicate measurements. 



Figure 7: Comparison of total organic carbon (TOC), total nitrogen (TN), and $\mathrm{UV}_{254}$ in the draw solution as a function of cumulative permeate volume after mitigation with: (A) GAC adsorption and (B) UV oxidation. Experimental conditions are shown in Figure 1. The amount of GAC used was $0.25 \mathrm{~g}$, and the power density and contact time of UV were $1.04 \mathrm{~W} / \mathrm{cm}^{2}$ and $25 \mathrm{~min}$, respectively. 

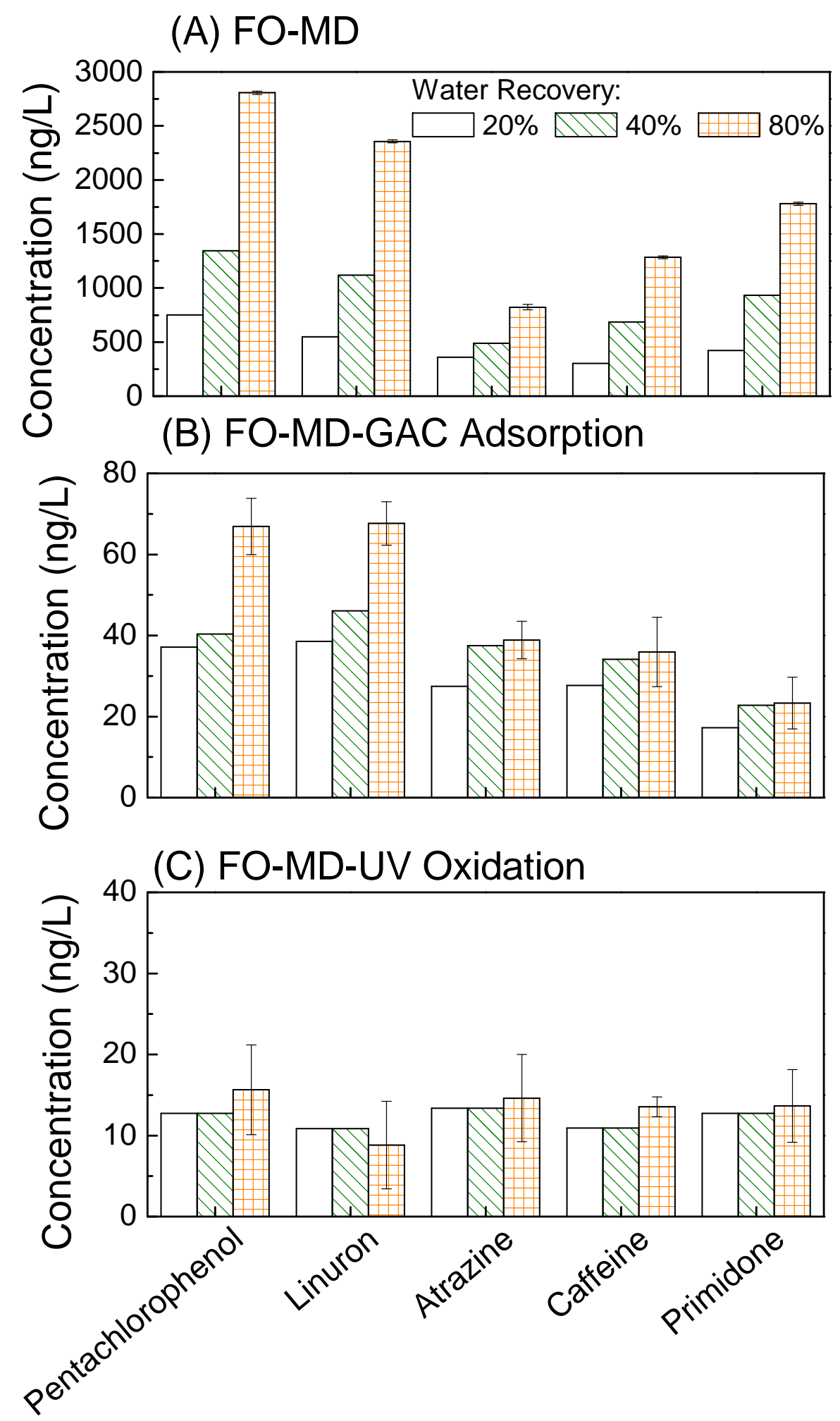

Figure 8: Comparison of TrOC concentrations in draw solution at different water recoveries by: (A) FO-MD, (B) FO-MD-GAC adsorption, and (C) FO-MD-UV oxidation. Experimental conditions are described in Figure 6. 